\title{
New Approach in Insulation System of Power Transformers - Insulating Oils with Less Impact on the Environment
}

\author{
R. Polanský, V. Mentlík, P. Prosr, P. Trnka and J. Pihera \\ Department of Technologies and Measurement \\ Faculty of Electrical Engineering, University of West Bohemia in Pilsen, \\ Univerzitní 26, 30614 Pilsen, Czech Republic, \\ Phone: +420 377634 517, e-mail: rpolansk@ket.zcu.cz
}

\begin{abstract}
Paper deals with comparison of selected properties of several vegetable oil representatives (commercially available ENVIROTEMP® FR ${ }^{\mathrm{TM}}$ vegetablebased transformer oil, sunflower oil, rape oil and refined sunflower and rape oil) along their accelerated thermal ageing at the temperature of $90{ }^{\circ} \mathrm{C}$. These properties are compared to two widely used and commercially available mineral transformer oils (Technol Y 3000 and Shell Diala DX). Combined insulating system (oil-paper system) was created with the usage of mentioned oils for measurement purposes. Dissipation factor, capacity and volume resistance are the characteristics measured along the thermal ageing of the oilpaper systems. Infrared spectroscopy was used as the additional method. After 1000 hours of ageing, the dissipation factor of all systems based on vegetable oils did not exceed the value of 0,015 . The volume resistance of systems containing mineral oils was approx. twice as high as volume resistance of those with vegetable oils. Capacity on the other hand was slightly lower in the case of mineral oils application. Experiment also showed that paper combined with vegetable oil dries more quickly than in combination with mineral oil. Infrared spectroscopy has not shown any expressive changes in the chemical structure of all tested oils yet. It was proven that all monitored electrical properties of commercially available ENVIROTEMP® FR3 ${ }^{\mathrm{TM}}$ transformer oil are very similar to the properties of common rape oil.
\end{abstract}

\section{Key words}

Power transformer, ecosystem, biodegradable oils, electrical properties.

\section{Introduction}

During the power transformer operation, some critical situations such as atmospheric discharge, turn-to-turn fault, diverter switch failure etc. can occur. Such situation could lead to the fire of the transformer, which would threaten both employees and environment. Soil contamination caused by transformer oil leakage or air contamination caused by burning products could also occur as the side effect. These situations have to be considered despite the low probability of their occurrence. To avoid environmental disaster we (besides the design set-ups - e.g. flood pool) look for acceptable replacement of currently used mineral (petroleum based) transformer oils. The mineral oils are known for their high flammability and very bad biodegradability [1] on the one hand and excellent properties (electrical, chemical etc.) on the other hand.

Transformer oils of the "new era" should have very good biodegradability, better thermal resistivity, stable electrical properties and also reasonable price. Therefore the main attention is currently given among others to financially reasonable and easily available vegetable oils (natural ester dielectric fluid) [2].

This problem has been being solved since the 80's of the last century and more and more attention is paid on it today [3-8]. It is known of natural esters that they have greater affinity for water than do mineral oils, so less water will remain in the paper as the water partitions itself between headspace, paper, and fluid. Water is consumed by hydrolysis of the natural ester, producing free fatty acids. These may react with the cellulose backbone via transesterification and protect the cellulose from hydrolysis. [4,6] There is a rich experience with practical application of these oils, e.g. McShane deals with these problems with great intensity. As written in his paper [3], the first prototype natural ester-filled transformers were installed in 1996. Since then, more than 150,000 distribution have been installed. More than 200 substation transformers have been built or retrofilled with natural ester fluid currently up to 200 MVA in base ratings and at voltages as high as $242 \mathrm{kV}$. Luksich also stated in his presentation at Weidmann-ACTI $3^{\text {rd }}$ Annual Technical Conference in Sacramento in 2004, that several transformers filled with natural ester fluids have been accessible for periodic fluid testing, including dissolved gas analysis. Changes in these transformers over time correspond to the changes predicted by accelerated life testing. In short, the types of changes seen in mineral oil are also typically seen in the natural ester fluids [7]. Another experience with practical application of natural esters are described e.g. in the work of Stockton [5]. Presented statements refer to promising future of these perspective fluids. 


\section{Objectives}

The main objective is to compare electrical properties and infrared spectra of chosen vegetable oils (oil-paper systems respectively). Commercially available ENVIROTEMP® FR $3^{\mathrm{TM}}$ vegetable-based transformer oil [8], sunflower oil, rape oil and refined sunflower and rape oil were exposed to the accelerated thermal ageing at the temperature of $90{ }^{\circ} \mathrm{C}$ for times ranging from 0 to 1000 hours. These oils were at the same time compared to two widely used and commercially available mineral transformer oils (Technol Y 3000 a Shell Diala DX).

\section{A. Specimen preparation}

Combined insulating system (oil-paper system) was created by diving of flat paper specimens (size of $100 \times 100 \mathrm{~mm}$, thickness of $1 \mathrm{~mm}$ ) to tested oils. During the whole experiment, oils together with paper specimens were placed in glass vessels and stayed closed along the thermal ageing by reason of partial restriction of air access.

\section{B. Method description}

Standard three-electrode system was used for the measurement of electrical characteristics (dissipation factor $\operatorname{tg} \delta[-]$, capacity $\mathrm{C}_{\mathrm{x}}[\mathrm{F}]$ and volume resistance $\mathrm{R}_{\mathrm{x}}$ $[\Omega])$. The electrode system was dived in tested oil together with paper specimen every time, when sampling was done - see Fig. 1.
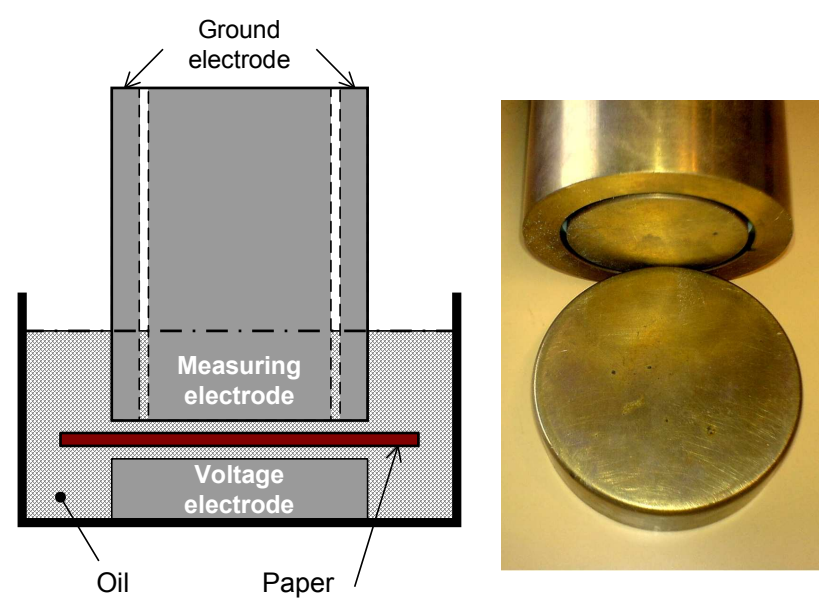

Fig. 1. Electrical test set-up.

During the dissipation factor and capacity measurement, three-electrode system was connected to automatic Schering Bridge (LDV-5 Lemke Diagnostics GmbH), during the volume resistance measurement, it was connected to electrometer with internal source of DC voltage of $500 \mathrm{~V}$ (Keithley Instruments, model 6517).

Infrared spectra (FT-IR spectra) were recorded on pure oils via Attenuated Total Reflectance technique (ATR) on Nicolet 380 spectrometer (Nicolet Instrument). Spectrometer was being purged by dry air during the measurement. Measurement was proceeded with $\mathrm{ZnSe}$ crystal, when 32 scans with a resolution of $4 \mathrm{~cm}^{-1}$ were collected for each specimen. Subsequent analysis of measured spectra was performed by OMNIC software.

\section{Thermal ageing}

Besides the measurement of above mentioned properties on virgin oils, these properties were measured also along the accelerated thermal ageing at $90{ }^{\circ} \mathrm{C}$ under limited access of air (see Fig. 2). Sampling was realized at the times after $0,50,125,225,500$ and 1000 hours of thermal ageing.

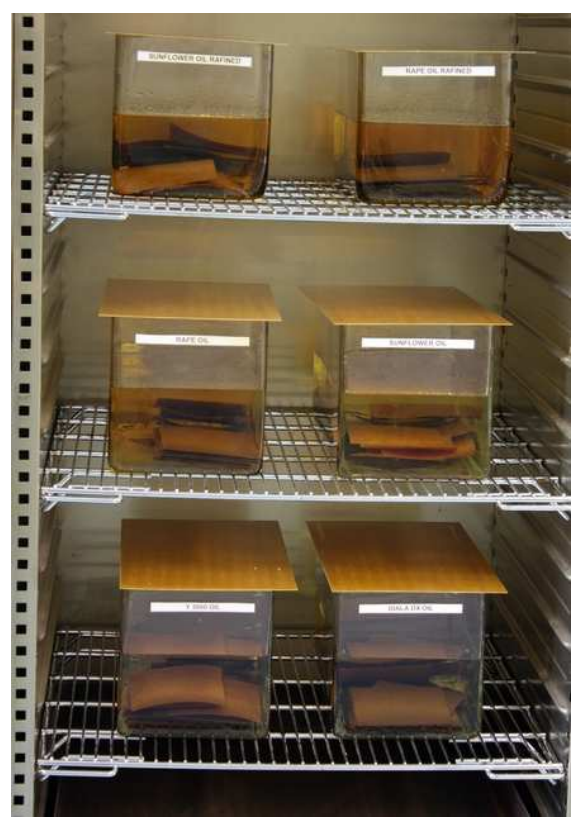

Fig. 2. Thermal ageing.

Sunflower and rape oils were also measured after alkaline refining according to $\mathrm{Li}[9]$ :

$$
\mathrm{RCOOH}+\mathrm{NaOH} \rightarrow \mathrm{RCOONa}+\mathrm{H}_{2} \mathrm{O}
$$

$0,6 \mathrm{mg}$ of $\mathrm{NaOH}$ was added to $1 \mathrm{~g}$ of oil. Sediments (coagulations) were removed through the usage of filter paper ( $8 \mu \mathrm{m}$ thickness of screen hole). This refining enabled to remove free fatty acids.

\section{Results}

\section{A. Electrical properties}

Following graphs (Fig. 3-5) show the results of electrical properties measurements. Dissipation factor dependence on time of thermal ageing is presented in Fig. 3. Although all oils and tested paper had been dried before testing (at $60{ }^{\circ} \mathrm{C}$ for 48 hours), high levels of dissipation factor were recorded at first $(\operatorname{tg} \delta=0,1-0,124$, i.e. $10-$ $12,4 \%$ of dielectric losses), which is most likely caused by high portion of residual moisture. This value improves expressively with the increasing time of thermal aging and dissipation factor thus refers to proceeding drying of the paper very well. The fact, that vegetable oils reach the optimum levels of dissipation factor (approx. 0,005 $0,01)$ more quickly than mineral oils, is very interesting (and it is fully in accordance with the conclusions of other authors [6]). This tendency was observed up to 500 
hours of thermal ageing. In the interval of $500-1000$ hours (see cut in Fig. 3), tan $\delta$ level of all tested insulating systems stabled in the range from 0,005 (Technol Y 3000) to 0,015 (Sunflower oil - refined).

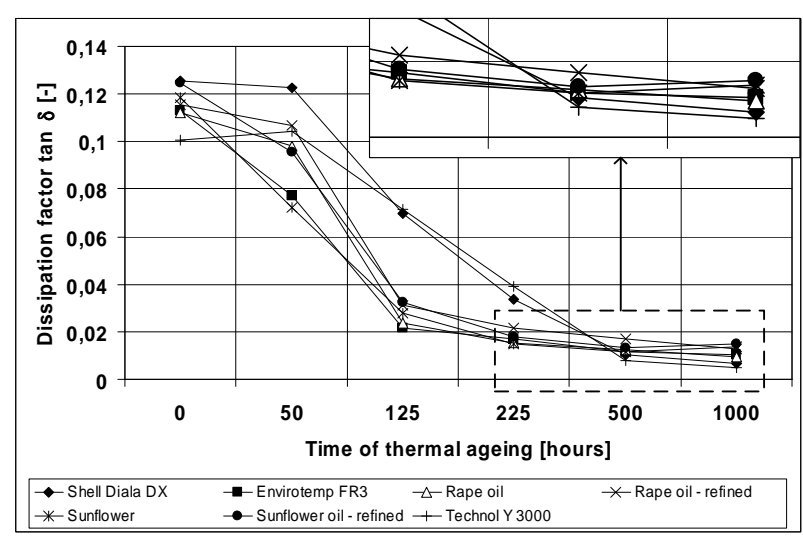

Fig. 3. Dissipation factor vs. thermal ageing.

Moisture in the inner structure of tested specimens was also proven by volume resistance evolution in dependence on the time of thermal ageing. (Fig. 4).

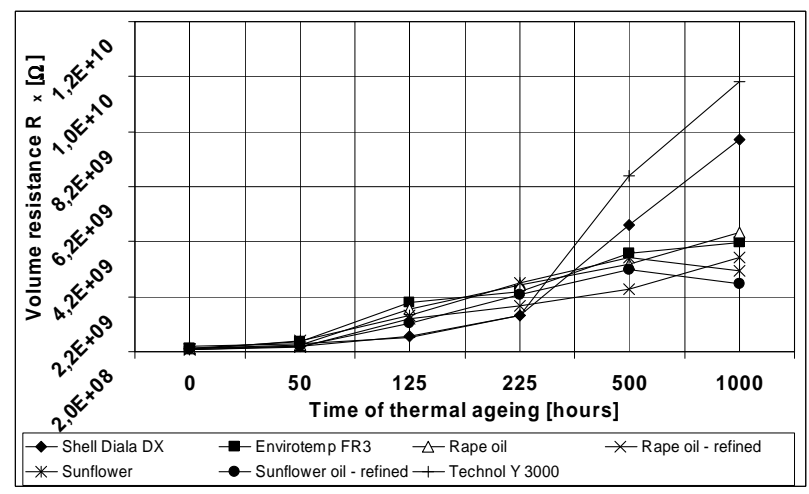

Fig. 4. Volume resistance vs. thermal ageing.

As obvious, expressive increase of volume resistance of all tested specimens was observed over the time owing to thermal ageing (2-order increase was observed). Also in this case, paper combined with vegetable oils dries more quickly up to $250-500$ hours of thermal ageing than does with mineral oils. This tendency changes in the time interval from 250 to 1000 hours.

Further the capacity influence on time of thermal ageing is presented in Fig. 5.

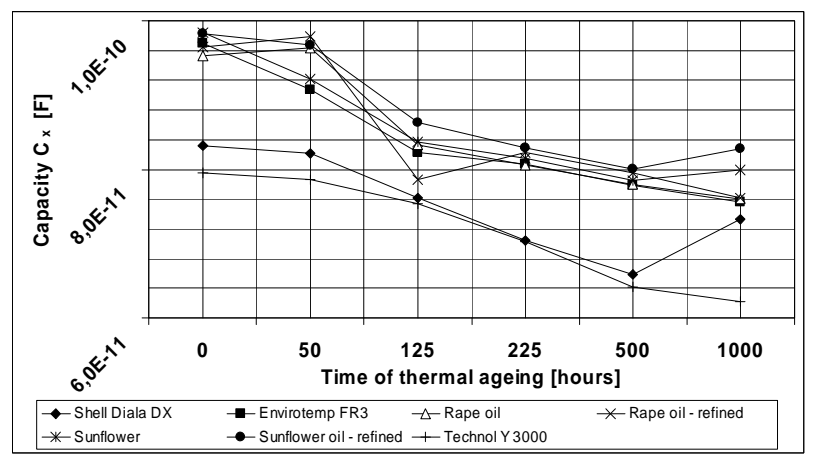

Fig. 5. Capacity vs. thermal ageing.
The capacity level is closely associated with level of relative permittivity. The higher the capacity (relative permittivity) is, the better the ability of the dielectric is to accumulate the electric charge, which is much undesired in the field of power transformers. Compared to previous plots, the difference between vegetable and mineral oil groups is obvious from the very beginning of capacity measurement. Insulating systems with mineral oils have slightly lower capacity level in general than systems containing vegetable oils.

\section{B. Fourier Transform Infrared Spectroscopy}

FT-IR spectroscopy was measured on pure oils removed from the vessels. The results of FT-IR spectroscopy refer to differences between vegetable and mineral oils very well from the view of their chemical structure. Following figure (Fig. 6) compares these differences of particular oil specimens.

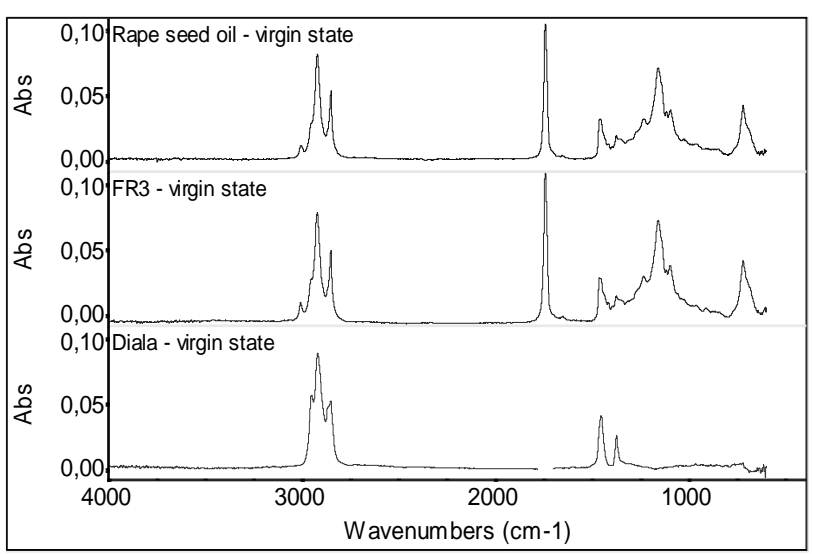

Fig. 6. Comparison of mineral and vegetable oils.

The most significant difference in oil spectra was observed in presence of strong band of $1743 \mathrm{~cm}^{-1}$ at vegetable oils (carbonyl stretching vibration), which marks the oxidative stability. In general, all oils containing oleic, linoleic and linolenic acid have lower oxidative stability considering a higher concentration of polyene fatty acids [10].

Another difference can be observed in fingerprint region from 1000 to $1300 \mathrm{~cm}^{-1}$. It is one of the specific spectrum regions, where vibration symmetry is very complicated and final absorption spectrum is unique for whole molecules or their functional groups.

Meanwhile, no significant change of obtained spectra of tested oils was observed when comparing oil spectra along the thermal ageing. In mineral oils, (see spectra of Technol Y 3000 oil in Fig. 7) intensity has not changed neither in the spectral bands of 3000 and $1460 \mathrm{~cm}^{-1}$, which correspond to hydrocarbons, nor in bands in the region from 800 to $712 \mathrm{~cm}^{-1}$, corresponding to refining level. Only slight change of intensity was observed in the frequency of $1157 \mathrm{~cm}^{-1}$.

Thermal ageing influenced the vegetable oils spectra even less than mineral oils spectra. This is obvious in Fig. 8, which shows the sunflower oil spectra for an example. As evident, single spectra almost overlap each other. 


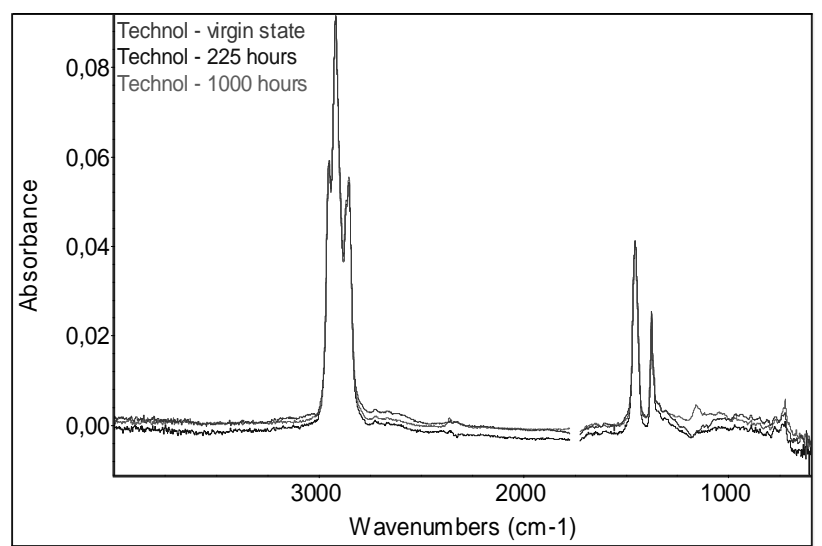

Fig. 7. IR spectra of mineral oil vs. thermal ageing (Technol Y 3000).

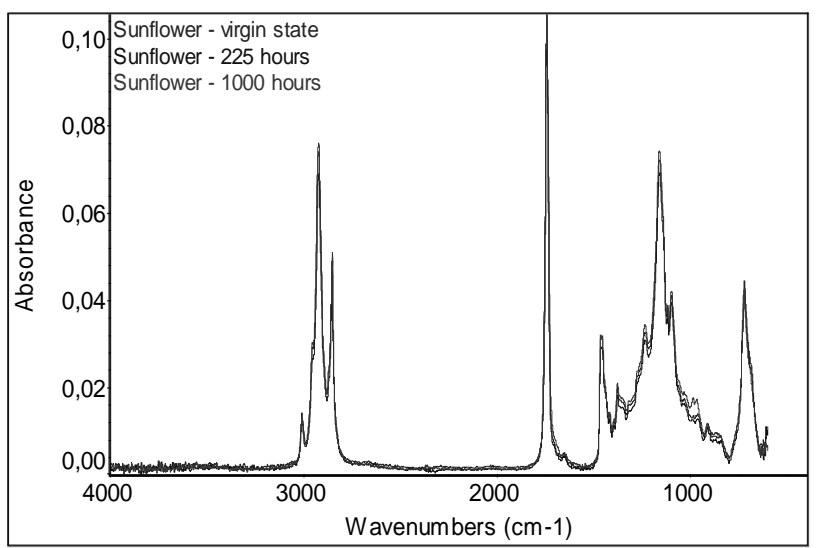

Fig. 8. IR spectra of vegetable oil vs. thermal ageing (sunflower oil).

\section{Conclusion}

Following conclusions after 1000 hours of thermal ageing can be drawn:

- The value of dissipation factor of all insulating systems containing vegetable oils does not exceed 0,015 . In spite of surprisingly good result, this value is still approx. $2-3$ times higher than the value of mineral oils.

- Volume resistance of systems containing mineral oils is approx. twice as high as volume resistance of systems with vegetable oils.

- Capacity is slightly lower in the case of mineral oils application then capacity of vegetable oils.

- Paper combined with vegetable oil dries more quickly than in combination with mineral oil.

- IR spectroscopy has not recorded any expressive changes in chemical structure of the tested oils yet.

- $\quad$ All observed electrical properties $\left(\mathrm{R}_{\mathrm{x}}, \tan \delta\right.$ and $\left.\mathrm{C}_{\mathrm{x}}\right)$ of paper combined with commercially available ENVIROTEMP ${ }^{\circledR} \quad$ FR3 ${ }^{\mathrm{TM}} \quad$ vegetable-based transformer oil are practically the same as in combination with rape oil. IR spectra of these two oils (Fig. 6) are also almost identical.
- Detailed analysis indicated the properties of paper and rape oil combination as the best from all tested vegetable specimens.

All obtained results confirm the good properties of mineral oils. This fact is caused mainly by their chemical structure. As mentioned above, big accent is put on application of environmental free materials nowadays, which requires as intensive research of alternative insulating oils (vegetable, synthetic oils eventually - see [11]) as that done in the past with mineral oils.

\section{Acknowledgement}

This article was carried out with the support of Ministry of Education, Youth and Sports of Czech Republic, MSM 4977751310 - Diagnostics of Interactive Processes in Electrical Engineering.

\section{References}

[1] I. Fofana, A. Bouaïcha1, M. Farzaneh, J. Sabau, „Ageing Behaviour of Mineral Oil and Ester Liquids: a Comparative Study", in IEEE Conference on Electrical Insulation and Dielectric Phenomena, Québec City, Canada, 2008, pp. 87-90.

[2] C. P. McShane, G.A. Gauger and J. Luksich, "Fire Resistant Natural Ester Dielectric Fluid and Novel Insulation System for Its Use", in IEEE/PES Transmission \& Distribution Conference, 1999, pp. 890-894.

[3] C. P. McShane, „Natural Ester Dielectric Fluid Development Update" in IEEE Power \& Energy Society General Meeting, 2009.

[4] C.P. McShane, J.L. Corkran, K.J. Rapp, J. Lnksich, ,Aging of paper insulation retrofilled with natural ester dielectric fluid“", in IEEE Annual Report Conference on Electrical Insulation and Dielectric Phenomena, 2003.

[5] D. P. Stockton, J. R. Bland, Jr., T. McClanahan, J. Wilson, D. L. Harris, P.E., P. McShane, „Natural Ester Transformer Fluids: Safety, Reliability \& Environmental Performance“ in IEEE Petroleum and Chemical Industry Technical Conference, 2007.

[6] Lijun Yang, Ruijin Liao, Caixin Sun, Huigang Sun, „Study on the Influence of Natural Ester on Thermal Ageing Characteristics of Oil-paper in Power Transformer" in IEEE International Conference on High Voltage Engineering and Application, Chongqing, China, November 9-13, 2008.

[7] J. Luksich, "Evaluating new and in-service vegetable oil dielectric fluids", presented at the Weidmann-ACTI 3rd Annual Technical Conference, Sacramento, CA, Nov.8-10, 2004.

[8] Cooper Power Systems, „Envirotemp ${ }^{\circledR}$ FR3 $^{\mathrm{TM}}$ Fluid“, Bulletin 00092, Cooper Power Systems, Inc. 2005.

[9] X. Li, J. Li, C. Sun, „Properties of Transgenic Rapeseed Oil Based Dielectric Liquid“, in IEEE SouthEastCon 2006, Memphis, TN, 2006, pp. 81-84.

[10] P. Kadlec et al., Food Technologies II (in Czech), The Institute of Chemical Technology, Prague (2002), pp. 89.

[11] V. Mentlík, R. Polanský, P. Prosr, J. Pihera, P. Trnka, „Synthetic Ester-Based Oils and Their Application in Power Industry“. in International Conference on Renewable Energies and Power Quality, Valencia, 2009. 